\title{
CINR Performance of Downlink Mobile WiMAX IEEE 802.16e Deployed Using Coexistence Cellular Terrestrial and HAPS
}

\author{
Iskandar \& Andi Wahyudi \\ Telecommunication Scientific Group, School of Electrical Engineering and Informatics \\ Institut Teknologi Bandung Jalan Ganesha No. 10, Bandung 40132, Indonesia \\ Email: iskandar@stei.itb.ac.id
}

\begin{abstract}
Deploying WiMAX through High Altitude Platform Station (HAPS) system is a new means of wireless delivery method and thus attracting much the attention in a telecommunication society. However delivering WiMAX through the terrestrial network has already been started a few years ago. Therefore, we need to look at the scenario of coexistence system both of HAPS and terrestrial in delivering WiMAX services. This paper evaluates the performance of coexistence system between cellular HAPS and terrestrial for the downlink scenario when they are transmitting WiMAX mobile 802.16e services. Our evaluation is based on the performance simulation of coexistence model using two methods. First method is a footprint exchange between the two systems. The second method is a combination of footprint exchange and HAPS footprint enhancement. The proposed methods are then evaluated by computer simulation in terms of carrier to interference plus noise ratio (CINR) performance. In general, both methods resulting performance enhancement in CINR quality compared with coexistence deployment with normal scenario of the cell configuration used by HAPS and terrestrial. The method of combining footprint exchange and HAPS footprint enhancement is able to improve CINR more than $10 \mathrm{~dB}$ compared with the normal footprint configuration for all users location inside the coverage.
\end{abstract}

Keywords: CINR; $E_{b} / N_{o}$; HAPS; QoS; Mobile WiMAX; Terrestrial.

\section{Introduction}

Providing worldwide interoperability for microwave access (WiMAX) in the $3.5 \mathrm{GHz}$ frequency band via HAPS is an effective step to provide wireless broadband communications [1]-[4]. In these literatures, coexistence performances of deploying WiMAX via HAPS and terrestrial have been evaluated in terms of capacity and channel performance. HAPS has been recommended by the International Telecommunication Union (ITU) as a novel wireless infrastructure to provide communication in the mm-wave broadband wireless access (BWA) communication frequency band and third-generation (3G) [5]-[7]. Investigations on HAPS have been focused on the mm-wave band

Received April $3^{\text {rd }}, 2013,1^{\text {st }}$ Revision March $21^{\text {st }}, 2014,2^{\text {nd }}$ Revision April 16 $6^{\text {th }}, 2014,3^{\text {rd }}$ Revision April $30^{\text {th }}$, 2014, Accepted for publication May $9^{\text {th }}, 2014$.

Copyright @ 2014 Published by ITB Journal Publisher, ISSN: 2337-5787, DOI: 10.5614/itbj.ict.res.appl.2014.8.1.5 
and code division multiple access (CDMA) scheme. HAPS system has many characteristics, i.e. high receiver elevation angle, line of sight (LOS) transmission, wide coverage area, and very large distribution of mobile users. These potential characteristics are making HAPS become very competitive to the conventional satellite and terrestrial system. At the same time this novel wireless system is able to provide overall better system performance, better capacity, and more cost-effective than conventional satellite or terrestrial system [8]-[13].

Mobile WiMAX (IEEE 802.16e) has now been developed in many countries in the world as a broadband wireless access technology that uses OFDMA as a multiple access technique [14]-[15]. Deploying mobile WiMAX through HAPS will become a phenomenal breakthrough for the world of telecommunications. With hundreds of WiMAX base stations carried by HAPS, this will make it much more cost-effective infrastructure. Meanwhile, WiMAX mobile users will enjoy a good quality of the channels provided by HAPS. But the problem will arise when mobile WiMAX is provided by HAPS system that coexist with mobile WiMAX provided by terrestrial system and share the same frequency band. We called it as a coexistence system [16] and will be our major evaluation in this paper.

\section{Mobile WiMAX System Profile}

Mobile WiMAX technology requires a standard that can be developed and used widely. For example modulation schemes that are considered in mobile WiMAX are BPSK, QPSK, 16-QAM and 64-QAM and the forward error correction (FEC) is chosen to be convolutional coding with the coding rates, i.e. $1 / 2,2 / 3,3 / 4$ and 1 (no-coding). Each combination of the modulation and coding modes gives one AMC mode. For adaptive modulation and coding, the transmit power from the RSs and the BSs should be kept constant. Many parameters can be used to evaluate the performance of mobile network, however we use cochannel interference parameter in this contribution to evaluate coexistence scenario between cellular HAPS and terrestrial.

As for comparison of mobile WiMAX parameter used in cellular network, Table 1 shows required CINR and spectral efficiency that can be achieved in practice. From that table we conclude that the higher the modulation level the better the spectral efficiency but the bigger the required CINR. It means to get a very good performance we need higher transmit power for high level modulation such as in 64-QAM modulation. In particular situation, such conclusion sometimes is incorrect due to a very high level of co-channel interference and also multipath fading. In this study, a case of downlink transmission of mobile WiMAX served from HAPS and terrestrial network is 
simulated under AWGN channel. The mobile WiMAX system profile defined by WiMAX Forum is used as a reference. The system parameters are listed in Table 2.

Table 1 Modulation and Coding Schemes (MCS).

\begin{tabular}{ccccc}
\hline No. & Modulation & Coding & $\begin{array}{c}\text { Required } \\
\text { CINR (dB) }\end{array}$ & $\begin{array}{c}\text { Spectral } \\
\text { Efficiency }\end{array}$ \\
\hline MCS1 & BPSK & 1 & 6.4 & 1 \\
MCS2 & QPSK & $1 / 2$ & 9.4 & 1 \\
MCS3 & QPSK & $3 / 4$ & 11.2 & 1.5 \\
MCS4 & 16-QAM & $1 / 2$ & 16.4 & 2 \\
MCS5 & 16-QAM & $3 / 4$ & 18.2 & 3 \\
MCS6 & 64-QAM & $2 / 3$ & 22.7 & 4 \\
MCS7 & 64-QAM & $3 / 4$ & 24.4 & 4.5 \\
\hline
\end{tabular}

Table 2 Mobile WiMAX System Profile.

\begin{tabular}{lc}
\hline \multicolumn{1}{c}{ Parameter } & Value \\
\hline Cell layout & 7 hexagon cells \\
Cell radius & $1400 \mathrm{~m}$ \\
Number of RS (per cell) & 6 \\
Duplex mode & TDD \\
Carrier frequency & $3.5 \mathrm{GHz}$ \\
Channel bandwidth & $10 \mathrm{MHz}$ \\
Sub-channel bandwidth & $262.5 \mathrm{kHz}$ \\
Frame duration & $5 \mathrm{~ms}$ \\
FFT size & 1024 \\
Antenna height & BS: $32 \mathrm{~m}, \mathrm{RS}: 15 \mathrm{~m}, \mathrm{MS}: 15 \mathrm{~m}$ \\
Antenna gain & BS: $14 \mathrm{~dB}, \mathrm{RS}: 12 \mathrm{~dB}, \mathrm{MS}: 0 \mathrm{~dB}$ \\
Antenna type & Omni-directional \\
Antenna number & $1 \mathrm{x} 1$ \\
Inter-site distance & BS-BS: $2.8 \mathrm{~km}$ \\
HHO threshold & $6 \mathrm{~dB}$ \\
MDHO threshold & $3 \mathrm{~dB}$ \\
Active Set size & 2 \\
Lognormal shadowing & $8.2 \mathrm{~dB}$ \\
Noise figure & Jakes spectrum \\
Fast fading & \\
\hline
\end{tabular}




\section{Coexistence Model}

The cellular concept is a breakthrough in solving the problem of limited spectrum and user's capacity. It offers high capacity in a limited spectrum allocation without making major changes in technology. The concept is a mobile concept at the system level with the idea to replace the transmitter with a high power (the wide cell) with a much lower transmitter power (a small cell). Each of which provides coverage to only a small portion of the service area. Like in terrestrial mobile concept, the entire frequencies or channels are assigned to each base station in a service area. Those channels are then used again in another base station and this concept refers to as frequency reuse technique. With this well-known technique the capacity of cellular system is dramatically increase compared with the system that uses conventional technique. However, this scheme is vulnerable to the co-channel interference which if we do not carefully design the system capacity would be dropped far away behind the conventional system capacity. Systematic way to provide space between the base station and the channel is through the market group. Available channels are distributed via geographic area and can be used again as needed during the interference among co-channel stations are under the level that can be received.

This basic principle is the foundation for all modern wireless cellular communication systems, because it allows a fixed number of channels to serve a large number of subscribers and change the repeat (reuse) channels through the coverage area. Furthermore, the concept of mobile equipment is designed to allow each subscriber in a country or continent uses the right-channel so that the same mobile equipment can be used anywhere and everywhere in a region. In order to simplify the model and hence evaluation, circular cell model is used to represent HAPS footprint which in the normal concept we used hexagonal shape. We also use $\mathrm{N}$ cells for one cluster so we consider the frequency reuse with the cluster size of $\mathrm{N}$ cells and they are using the same frequency. From the basic of cellular concept, $\mathrm{N}$ is formulated using the following equation.

$$
\mathrm{N}=\mathrm{I}^{2}+\mathrm{J}^{2}+(\mathrm{I} \times \mathrm{J}), \quad \mathrm{I}, \mathrm{J}=0,1,2,3, \ldots
$$

Hence, we evaluate 3, 4, and 7 as possible values for $\mathrm{N}$ (cluster size). Accordingly, the minimum distance (D) between the co-channel cells is a function of $\mathrm{N}$ and $\mathrm{R}$ (cell radius) and given as [17],

$$
\mathrm{D}=\mathrm{R} \sqrt{3 \mathrm{~N}}
$$

Figure 1 shows an example of frequency reuse patterns over HAPS cellular system using cluster size $\mathrm{N}=7$. Co-channel cells are depicted with the same color. Frequency reuse allows the use of same frequency already employed in 
other cells nearby, thus allowing frequencies to be used for multiple simultaneous communications.

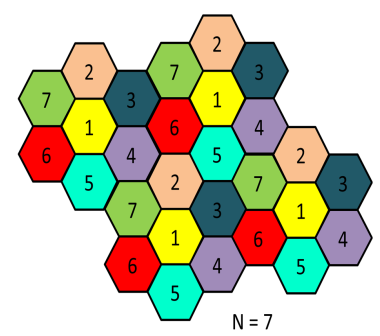

Figure 1 Frequency Reuse with Cluster Size of 7.

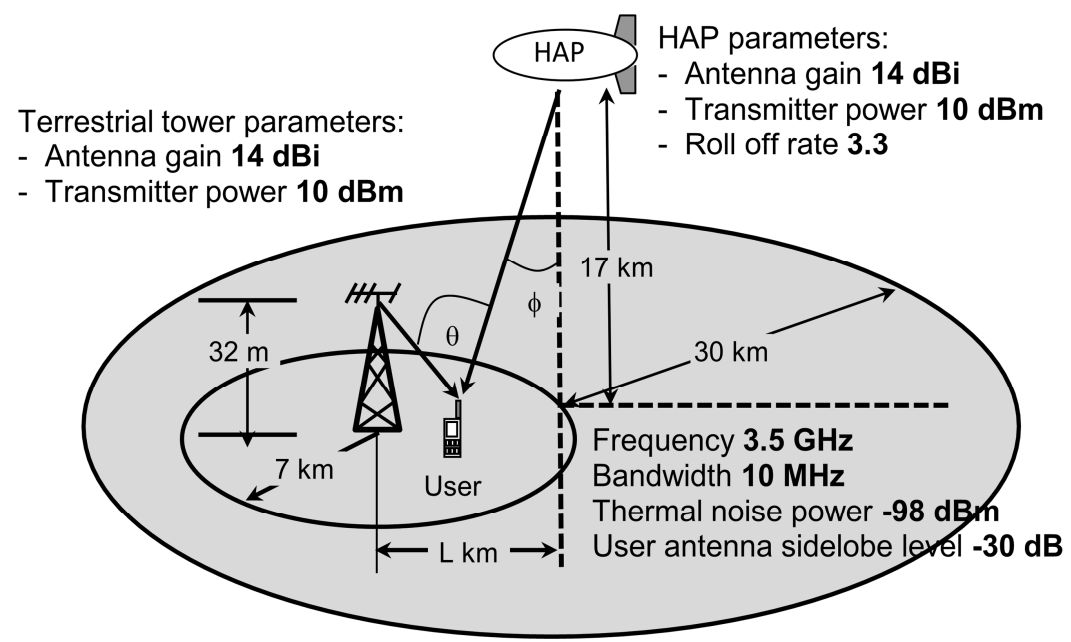

Figure 2 Coexistence Scenario.

Although HAPS propagation model has been studied in particular research for frequency in 3,5 GHz such as intended for the use of WiMAX system, it is not so much result in propagation study. An extremely high position of HAPS lead to the free space model for propagation rather than propagation model for terrestrial in which it includes many reflection and multipath propagation. Geometry of HAPS communication brings many users who are located near the cell center to have a line of sight path to look at to HAPS. Even some reflections and diffractions contribute to the propagation but for the high elevation angle user (user that located near nadir), the propagation model can be approached by free space loss model. Free space loss model is a well-known 
propagation model which includes frequency and distance between HAPS and user using the following formula.

$$
L p_{H}=32.45+20 \log f_{M H z}+20 \log d_{K m}
$$

In Figure 2, the main issue must be considered in this modeling. The use of the same frequency band between HAPS and terrestrial system called coexistences will be tested in this paper. Parameters of the system simulation model are specifications for Mobile WiMAX 802.16e and WiMAX HAPS [18]-[19].

Cell configuration used in modeling cellular HAPS is described in Figure 3. It is considered that there is only a single HAPS employed by multibeam antenna floating at an altitude of $17 \mathrm{~km}$ serving multiple cells. The radius of HAPS coverage area depends on the elevation angle, for example if elevation angle is $5^{0}$, coverage radius will be near $100 \mathrm{~km}$. However in our model we assume that HAPS coverage is about $30 \mathrm{~km}$ which refers to the elevation angle of $50^{\circ}$. HAPS cell radius is assumed to be of $8 \mathrm{~km}$. We assume that the simulated number of cells in our simulation is 19 and they are hexagonally arranged and clustered in different frequency reuse patterns to cover the whole HAPS service area.

Table 3 Cell Coordinate.

\begin{tabular}{llll}
\hline $\mathrm{C} 1=(0,0)$ & $\mathrm{C} 6=(-2 \mathrm{a}, 0)$ & $\mathrm{C} 11=(4 \mathrm{a}, 0)$ & $\mathrm{C} 16=(-3 \mathrm{a},-1.5 \mathrm{r})$ \\
$\mathrm{C} 2=(\mathrm{a}, 1.5 \mathrm{r})$ & $\mathrm{C} 7=(-\mathrm{a}, 1.5 \mathrm{r})$ & $\mathrm{C} 12=(3 \mathrm{a},-1.5 \mathrm{r})$ & $\mathrm{C} 17=(-4 \mathrm{a}, 0)$ \\
$\mathrm{C} 3=(2 \mathrm{a}, 0)$ & $\mathrm{C} 8=(0,3 \mathrm{r})$ & $\mathrm{C} 13=(2 \mathrm{a},-3 \mathrm{r})$ & $\mathrm{C} 18=(-3 \mathrm{a}, 1.5 \mathrm{r})$ \\
$\mathrm{C} 4=(\mathrm{a},-1.5 \mathrm{r})$ & $\mathrm{C} 9=(2 \mathrm{a}, 3 \mathrm{r})$ & $\mathrm{C} 14=(0,-3 \mathrm{r})$ & $\mathrm{C} 19=(-2 \mathrm{a}, 3 \mathrm{r})$ \\
$\mathrm{C} 5=(-\mathrm{a},-1.5 \mathrm{r})$ & $\mathrm{C} 10=(3 \mathrm{a}, 1.5 \mathrm{r})$ & $\mathrm{C} 15=(-2 \mathrm{a},-3 \mathrm{r})$ & \\
\hline
\end{tabular}

The numbering of the cells is intended not only as a reuse frequency allocation scheme but also to make easy in simulation and positioning. The cell coordinate of each cell is determined first and the result is represented in Table 3. It is used as terrestrial footprint coordinate or HAPS footprint coordinate both in cells footprint exchange method and in enlargement and cells footprint exchange method. System that coexistence between the HAPS base station (H-BS) with the terrestrial base station (T-BS), such as in Figure 4, provides mutual interference in each user if the system uses the same frequency or called cochannel interference. Position of this co-channel cell depends on the cluster size used by the system. The larger the clusters size the farther the distance among co-channel cells. Therefore the interference level that occurs at the testing cell will be smaller. In addition, enlargement of the cluster size will decrease the number of co-channel cells so that the number of cells that interfere the other cells will be on the wane. An antenna radiation pattern is an important thing and critical design factor in determining the performance of radio communication 
systems. Ideally in cellular system, the antenna pattern would radiate uniform power across its serving cell and no power should fall outside. In practice, there is unavoidably power spilling outside the coverage area, which can cause interference to other cells.

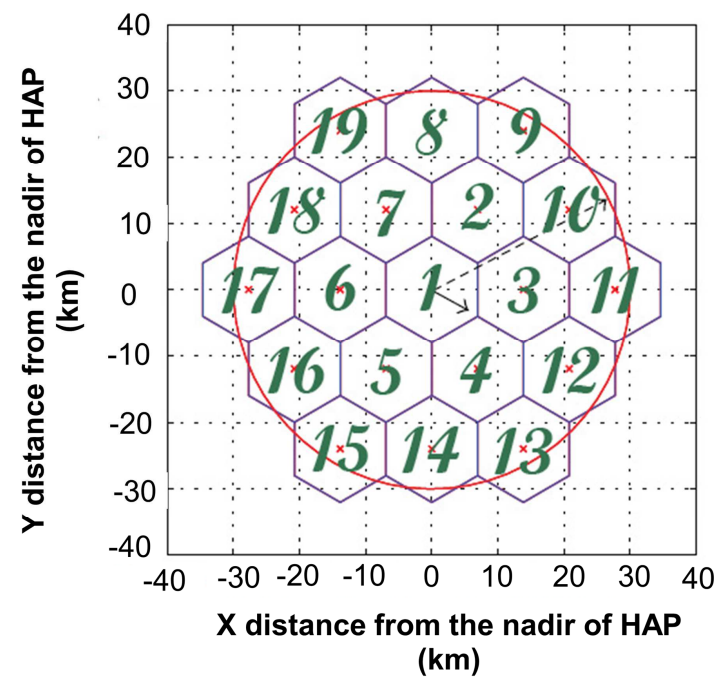

Figure 3 Cell Number.

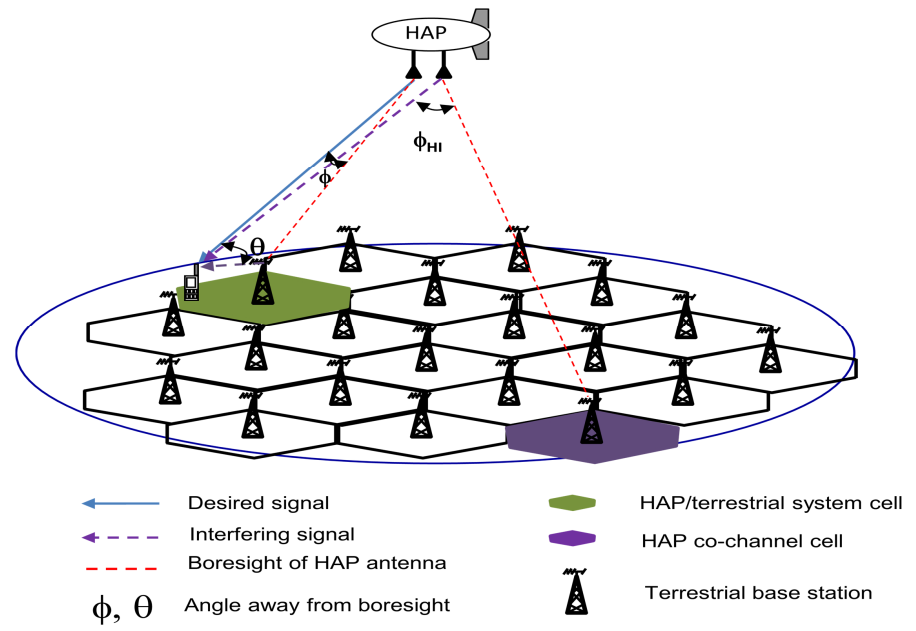

Figure 4 Cell Number. 
In this paper, we employ a directive antenna pattern in [1], [2], [20]-[22], which can ensure more power radiated in the desired directions and decrease the power radiated towards undesired directions, on both the HAPS and ground user [23][26]. Antenna models are presented in (1) and (2), respectively. The gain $A_{H}(\varphi)$ of the HAPS antennas at an angle $\varphi$ with respect to its boresight, and that of the ground receiver antenna $A_{U}(\theta)$ at an angle $\theta$ away from its boresight are approximated by a cosine function raised to a power roll-off factor $n$ and $a$ notional flat sidelobe level $s_{f}$. $G_{H}$ and $G_{U}$ represent the boresight gain of the HAPS antennas and user antenna, respectively [24]:

$$
\begin{aligned}
& \mathrm{A}_{\mathrm{H}}(\varphi)=G_{H}\left(\max \left[\cos ^{n H}(\varphi), s_{f}\right]\right) \\
& \mathrm{A}_{\mathrm{U}}(\theta)=G_{U}\left(\max \left[\cos ^{n U}(\theta), s_{f}\right]\right)
\end{aligned}
$$

Figure 5 shows the curve resulted from this equation by using proposed parameters. Following equations describe the relationship between terrestrial and HAPS system in terms of the downlink performance.

1. Downlink coexistence performance of the T-BS to the user (performance experienced by terrestrial users):

$$
\begin{aligned}
\operatorname{CIR}_{T U, H} & =\frac{\left[P_{T} A_{T} A_{U}(\theta)\right] / P L_{T U}}{\sum_{i=1}^{N_{H}}\left[P_{H i} A_{H i}(\varphi) A_{U i}(\theta)\right] / P L_{H i U}+\sum_{i=0}^{N_{T}}\left[P_{T i} A_{T i} A_{U i}(\theta)\right] / P L_{T i U}} \\
\operatorname{CINR}_{T U, H} & =\frac{\left[P_{T} A_{T} A_{U}(\theta)\right] / P L_{T U}}{N_{F}+\sum_{i=1}^{N_{H}}\left[P_{H i} A_{H i}(\varphi) A_{U i}(\theta)\right] / P L_{H i U}+\sum_{i=0}^{N_{T}}\left[P_{T i} A_{T i} A_{U i}(\theta)\right] / P L_{T i U}}(7)
\end{aligned}
$$

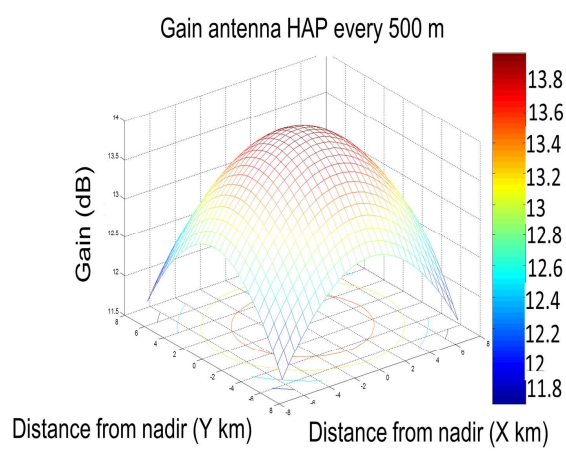

(a) HAPS Antenna.

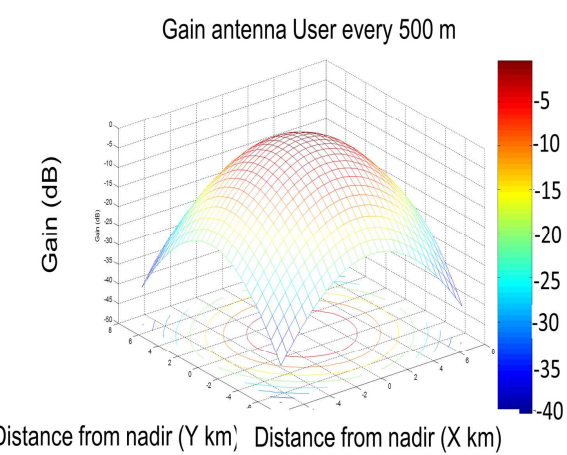

b) User Antenna.

Figure 5 User's and HAPS's antenna gain.

2. Downlink coexistence performance of the H-BS to the user (performance experienced by HAPS user): 


$$
\begin{aligned}
& C I R_{H U, T}=\frac{\left[P_{H} A_{H}(\varphi) A_{U}(\theta)\right] / P L_{H U}}{\sum_{i=0}^{N_{H}}\left[P_{H i} A_{H i}(\varphi) A_{U i}(\theta)\right] / P L_{H i U}+\sum_{i=1}^{N_{T}}\left[P_{T i} A_{T i} A_{U i}(\theta)\right] / P L_{T i U}} \\
& \operatorname{CINR}_{H U, T}= \\
& \frac{\left[P_{H} A_{H}(\varphi) A_{U}(\theta)\right] / P L_{H U}}{N_{F}+\sum_{i=0}^{N_{H}}\left[P_{H i} A_{H i}(\varphi) A_{U i}(\theta)\right] / P L_{H i U}+\sum_{i=1}^{N_{T}}\left[P_{T i} A_{T i} A_{U i}(\theta)\right] / P L_{T i U}}
\end{aligned}
$$

\begin{tabular}{|c|c|c|}
\hline$C I R_{H U, T}$ & & $\begin{array}{l}\text { Carrier to Interference Ratio from HAPS to user and coexisting } \\
\text { with the terrestrial system. }\end{array}$ \\
\hline$C I N R_{H U, T}$ & & $\begin{array}{l}\text { Carrier to Interference plus Noise Ratio from HAPS to user and } \\
\text { coexisting with the terrestrial system. }\end{array}$ \\
\hline$C I R_{T U, H}$ & & $\begin{array}{l}\text { Carrier to Interference Ratio from Terrestrial to user and } \\
\text { coexisting with the HAPS system. }\end{array}$ \\
\hline$C I N R_{T U, H}$ & & $\begin{array}{l}\text { Carrier to Interference plus Noise Ratio from Terrestrial to user } \\
\text { and coexisting with the HAPS system. }\end{array}$ \\
\hline$P_{H}$ & & Power transmit by the HAPS antenna \\
\hline$P_{T}$ & & Power transmit by the Terrestrial antenna \\
\hline$A_{T}$ & & Antenna Gain of T-BS \\
\hline$N_{H}$ & & Number of HAPS co-channel cell using the same frequency \\
\hline$N_{T}$ & & Number of Terrestrial co-channel cell using the same frequency \\
\hline$N_{F}$ & & Noise Power. \\
\hline
\end{tabular}

where

\section{Proposed Method}

In order to reduce interference perceived by terrestrial and HAPS users due to signal coming from H-BS or T-BS we employ the following two methods. First method is a cell exchange between HAPS cell and terrestrial cell as described in Figure 6(a). We employ the cluster size of 7 in our simulation which means there are 7 different cells operating at different frequency. To minimize interference between T-BS and H-BS we exchange the cell of HAPS to move away from cell terrestrial. This technique allows each H-BS moves away to different position that is far enough from co-channel cell of T-BS to avoid colocation. Finally, HAPS cells configuration is changed from initial arrangement to reduce interference. Cells footprint exchange method have the principle that the more remote from the source of co-channel interference then the influence of interference will decrease. This method does not reduce or enlarge the size of the cell so that it does not affect the amount of frequency reuse in the system.

Enlarge and exchange cells footprint method have consequences that HAPS cells footprint are bigger. As is known, more remote from the center of the cells, because of larger cells, performance experienced by the users will decrease. Now let we simulate terrestrial footprint and HAPS footprint using 1/7 reuse 
factor. This method is performed by placing the cells in the HAPS and terestrial position clear of each other between the same footprints. This result reduces the influence of co-channel interference that comes from HAPS and terestrial.

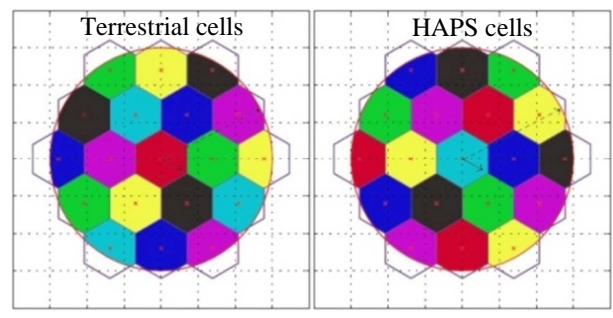

(a)

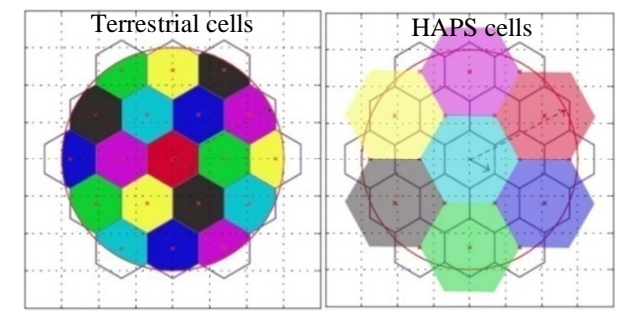

(b)

Figure 6 Proposed method to improve CINR using 7 cell reuse pattern: (a) Cells footprint exchange, (b) Enlargement and cell footprint exchange.

The second method of improving user's performance in a coexistence deployment of WiMAX HAPS and terrestrial is performed by combination of cell exchange and HAPS cell enlargement. Figure 6 (b) shows the application of this method. While we are doing cell exchange like in the first method, we also enlarge the size or radius of HAPS cell. In this experiment we perform cell enlargement by $\sqrt{ } 3$ times the radius of the terrestrial footprint cells and place them in a position farthest from the same color. With this method the probability of a user suffers from signal interference is reduced by their possibility location to the larger area then it is not enlarged. By calculating all possibility locations inside the enlarged cell, CINR of a user can be obtained by computer simulation. In our simulation, some technical parameters for terrestrial and HAPS are set to be the same and some other is specific as presented in Table 4.

In the simulation we assume that there are 19 cells projected from HAPS base station and also 19 cells produced by terrestrial base station using 7 cells reuse pattern. It means that we consider up to two layers of cells contribute as cochannel cells. There are 4 possibilities of user's situation during which they received co-channel interference from co-channel cells. We create cell identity to indicate that cell belongs to terrestrial base station or HAPS base station. For example cell with initial identity number TC means that cell belongs to terrestrial base station and HC belongs to HAPS base station. Therefore there are 19 TC from TC-1 up to TC-19 and also there are 19 HC from HC-1 up to HC-19. We assume that there are three scenarios and four possibilities of cochannel interference produced to reference cell. 
Table 4 Evaluation Parameters.

\begin{tabular}{|c|c|c|}
\hline Parameter & H-BS & T-BS \\
\hline Coverage Radius & $30 \mathrm{~km} \quad\left(\mathrm{R}_{\mathrm{H}}\right)$ & $\begin{array}{lll}7 & \mathrm{~km} & \left(\mathrm{R}_{\mathrm{T}}\right)\end{array}$ \\
\hline Transmitter Height & $17 \mathrm{~km} \quad\left(\mathrm{H}_{\mathrm{H}}\right)$ & $32 \mathrm{~m}$ \\
\hline Transmitter Power & $40 \mathrm{dBm}\left(\mathrm{P}_{\mathrm{H}}\right)$ & $40 \mathrm{dBm}\left(\mathrm{P}_{\mathrm{T}}\right)$ \\
\hline Antenna Gain & $14 \mathrm{dBi} \quad\left(\mathrm{G}_{\mathrm{H}}\right)$ & $14 \mathrm{dBi}\left(\mathrm{A}_{\mathrm{T}}\right)$ \\
\hline Roll-off Rate & $3.3 \quad\left(\mathrm{n}_{\mathrm{H}}\right)$ & N/A \\
\hline Antenna Efficiency & \multicolumn{2}{|c|}{$80 \%$} \\
\hline User Roll-off Rate & \multicolumn{2}{|c|}{$58 \quad\left(\mathrm{n}_{\mathrm{U}}\right)$} \\
\hline User Boresight Gain & \multicolumn{2}{|c|}{$0 \mathrm{~dB} \quad\left(\mathrm{G}_{\mathrm{U}}\right)$} \\
\hline User Antenna Height & \multicolumn{2}{|c|}{$1.5 \mathrm{~m}\left(\mathrm{H}_{\mathrm{U}}\right)$} \\
\hline Sidelobe Level & \multicolumn{2}{|c|}{$-30 \mathrm{~dB}\left(\mathrm{~s}_{\mathrm{f}}\right)$} \\
\hline Bandwidth & \multicolumn{2}{|c|}{$10 \mathrm{MHz}$ DL/UL (TDD) } \\
\hline Frequency & \multicolumn{2}{|c|}{$3.5 \mathrm{GHz}$} \\
\hline Thermal Noise Floor & \multicolumn{2}{|c|}{$-98 \mathrm{dBm}\left(\mathrm{N}_{\mathrm{F}}\right)$} \\
\hline
\end{tabular}

\section{Simulation Result}

Now we focus on the simulation result in which evaluation considered for three scenarios. Those are overlapping situation between HAPS and terrestrial footprint, cell exchange between terrestrial and HAPS footprint, and the third scenario is cell exchange combine with cell enlargement of HAPS footprint. The simulation results are presented using the curve of CINR spreading on the area of each cell from the center to the edge in three-dimensional form. Shape of the CINR curve depends on position of co-channel cells that causing interference. Level of CINR perceived by a user is caused by the number of cochannel interference cell. Co-channel interference cell for overlapping scenario, cell exchange scenario, and cell exchange and cell HAPS enlargement scenario are shown in Table 5, Table 6, and Table 7, respectively.

Table 5 Overlapping Scenario.

\begin{tabular}{cll}
\hline $\begin{array}{c}\text { User } \\
\text { Possibility } \\
\text { Location }\end{array}$ & \multicolumn{1}{c}{ Co-channel interferer cell } \\
\cline { 2 - 3 } & \multicolumn{1}{c}{ User test: user terrestrial } & \multicolumn{1}{c}{ User test: User HAPs } \\
\hline 1 & TC-1, HC-1 & HC-1 : TC-1 \\
2 & TC-3: TC-16, TC-19, HC-3, HC- & HC-3 : HC-16, HC-19, TC- \\
& 16, HC-19 & 3, TC-16, TC-19 \\
3 & TC-10: TC-6, TC-13, HC-6, HC- & HC-10 : HC-6, HC-13, TC- \\
& 10, HC-13 & 6, TC-10, TC-13 \\
4 & TC-11: TC-5, TC-8, HC-5, HC-8, & HC-11: HC-5, HC-8, TC-5, \\
& HC-11 & TC-8, TC-11 \\
\hline
\end{tabular}


Table 6 Cell Exchange Scenario.

\begin{tabular}{cll}
\hline $\begin{array}{c}\text { User } \\
\text { Possibility } \\
\text { Location }\end{array}$ & \multicolumn{1}{c}{ Co-channel interferer cell } \\
\cline { 2 - 3 } User test: user terrestrial & \multicolumn{1}{c}{ User test: User HAPs } \\
\hline 1 & TC-1 : HC-2, HC-14, HC-17 & HC-1 : TC-7, TC-12, TC-15 \\
2 & TC-3: TC-16, TC-19, HC-4, & HC-2 : HC-14, HC-17, TC-1 \\
& HC-9, HC-18 & \\
3 & TC-7 : TC-12, TC-15, HC-1 & HC-3: HC-16, HC-19, TC-2, \\
& & TC-14, TC-17 \\
4 & TC-10 : TC-6, TC-13, HC-7, & HC-10 : HC-6, HC-13, TC-5, \\
& HC-12, HC-15 & TC-8, TC-11 \\
\hline
\end{tabular}

Table 7 Cell Exchange and Cell HAPS Enlargement Scenario.

\begin{tabular}{cll}
\hline $\begin{array}{c}\text { User } \\
\text { Possibility } \\
\text { Location }\end{array}$ & \multicolumn{1}{c}{ Co-channel interferer cell } \\
\cline { 2 - 3 } & \multicolumn{1}{c}{ Usert: user terrestrial } & \multicolumn{1}{c}{ User test: User HAPs } \\
\hline 1 & TC-1 : HC-10 & HC-1 : TC-7, TC-12, TC-15 \\
2 & TC-3: TC-16, TC-19, HC-14 & HC-10: TC-1 \\
3 & TC-7 : TC-12, TC-15, HC-1 & HC-12: TC-2, TC-14, TC-17 \\
4 & TC-10: TC-6, TC-13, HC-8 & - \\
\hline
\end{tabular}

Now we describe CINR of user terrestrial and user HAPS for the scenario of overlapping using reuse factor of $1 / 7$. There are 4 possibility of cell co-channel interferer which resulting 4 possible CINR. Figure 7 shows terrestrial user position at the center of the cell has the biggest CINR means that it receives less interference compare to that at the edge position in the cell. CINR of user HAPS is depicted in Figure 8. We can see that user HAPS located at the cell center also receives less interference such as user terrestrial, but CINR user HAPS at cell center has bigger CINR than that of terrestrial user. It is occur because the better channel condition from HAPS which is line of sight path compared with Rayleigh channel experienced by terrestrial user. Another point that can be drawn from this overlapping scenario is that all users have significant degradation in the CINR performance when they move from center to the cell edge. This condition would have been anticipated with footprint exchange scenario and also in cell enlargement scenario.

From both figure interference level for user possibility location 1 has the higher CINR than that for user possibility location 2,3 , and 4 . This because the number of co-channel cell for user possibility location 1 is only 2 co-channel cell while for user possibility location 2, 3, and 4 are more than two c-channel cell. At the cell center, users suffer less co-channel interference compared with at the edge cell. However the degradation of CINR from center to edge 
experienced by a user terrestrial is faster than that of experienced by user HAPS. That means line of sight situation of HAPS give major contribution to an interference level but also in improving signal quality.
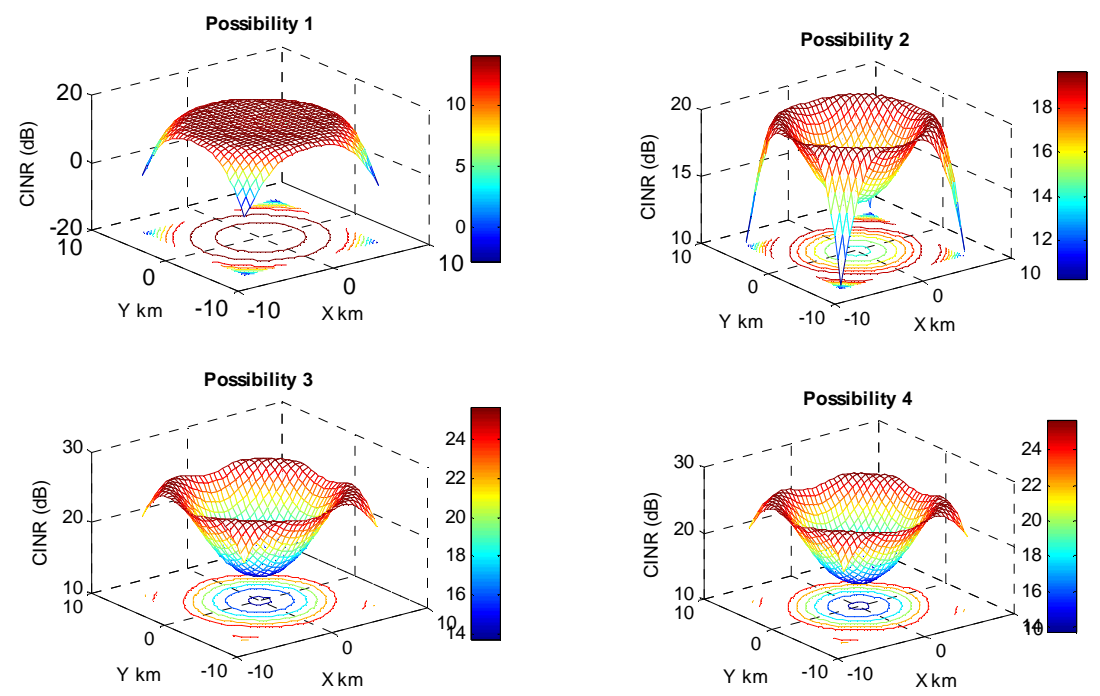

Figure 7 CINR user HAPS in overlapping scenario using reuse factor 1/7.
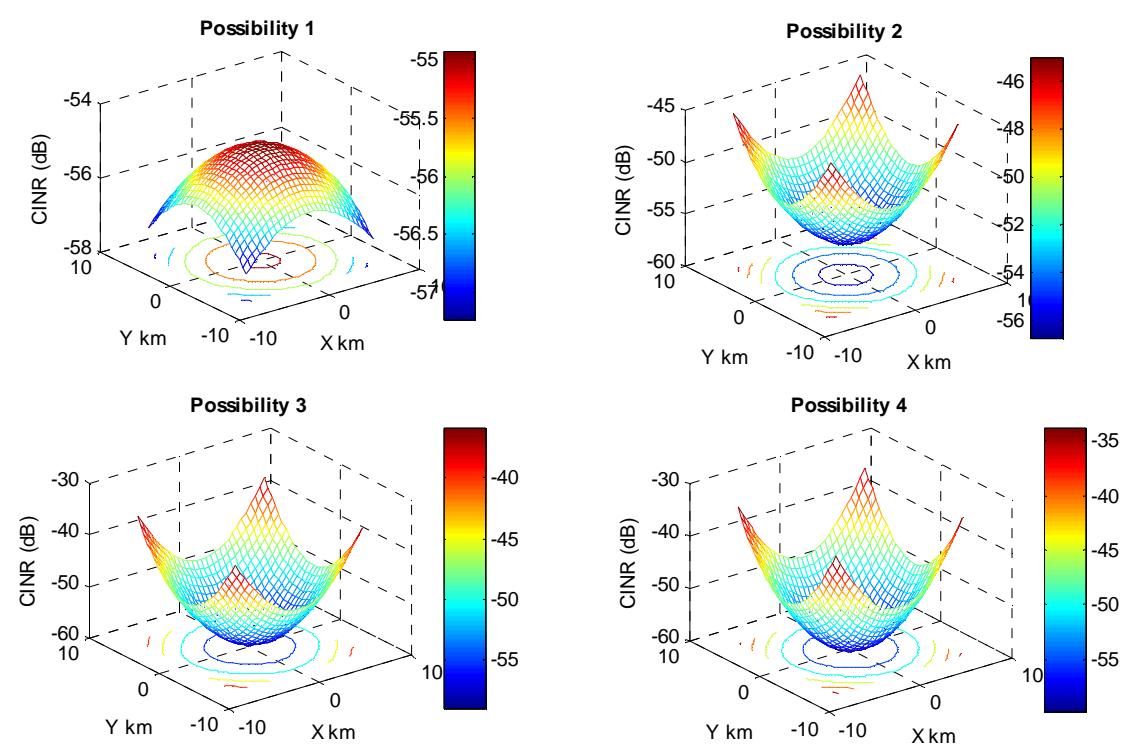

Figure 8 CINR user HAPS in overlapping scenario using reuse factor 1/7. 
User's terrestrial and user's HAPS in cell exchange algorithm have experienced better CINR performance compared with the overlapping algorithm. This is easy to analyze because co-channel cell between HAPS footprint and terrestrial footprint over which they are exchanged each other is decreasing. It is resulting not only better CINR for cell terrestrial but also for cell HAPS from cell center to cell edge. Figure 9 shows CINR perceived by user terrestrial is decreasing compared with that in overlapping scenario. However CINR of user HAPS as depicted in Figure 10 is increasing because after we counted for co-channel cell, we also considered that propagation path is better in HAPS channel than that in terrestrial channel.

This is because cells footprint exchange method follows the principle that the cell located far from the source of the interference then co-channel interference effect will decrease. This method does not reduce or enlarge the cell size so it is not affect the number of frequency reuse in the system. By looking at the patterns of terrestrial cell footprint, there will be interference signal coming from H-BS into T-BS due to sidelobe antenna gain from H-BS. To this point we simulate this scenario by taking pattern representation with the same distance in order to get all possible performance of the terrestrial user. Therefore CINR maximum is experienced by users located at the center of the cell. When they move to the cell edge, CINR is decreasing but for the users HAPS moving to the edge causing CINR decreasing more rapidly. This fact is explained as follows. When users HAPS move to the edge, and at the same time cell exchange between co-channel cell terrestrial and co-channel cell HAPS is being conducted, there will be strong signal comes from co-channel cell terrestrial hit to the users HAPS at their location. However in general, exchange cell scenario performs better performance compared with overlapping cell scenario. This improvement proposed as a solution to overlapping scenario.

Footprint exchange method shows the improvement in CINR perceived by the user who is located near the edge of the cell both for user terrestrial and also for user HAPS. Footprint exchange method comes from idea that the cell number refers to the specific cell frequency is exchanged between terrestrial and HAPS so that co-channel interference occur in the test user is less. Also footprint exchange is able to extent the cell size without additional co-channel interference. However we have to consider the number of cell that can be exchanged because if all cells in the cluster are changed then the scenario will have no different scenario with overlapping scheme. With cell enlargement we can also improved CINR and also capacity because the cluster size is improved. 

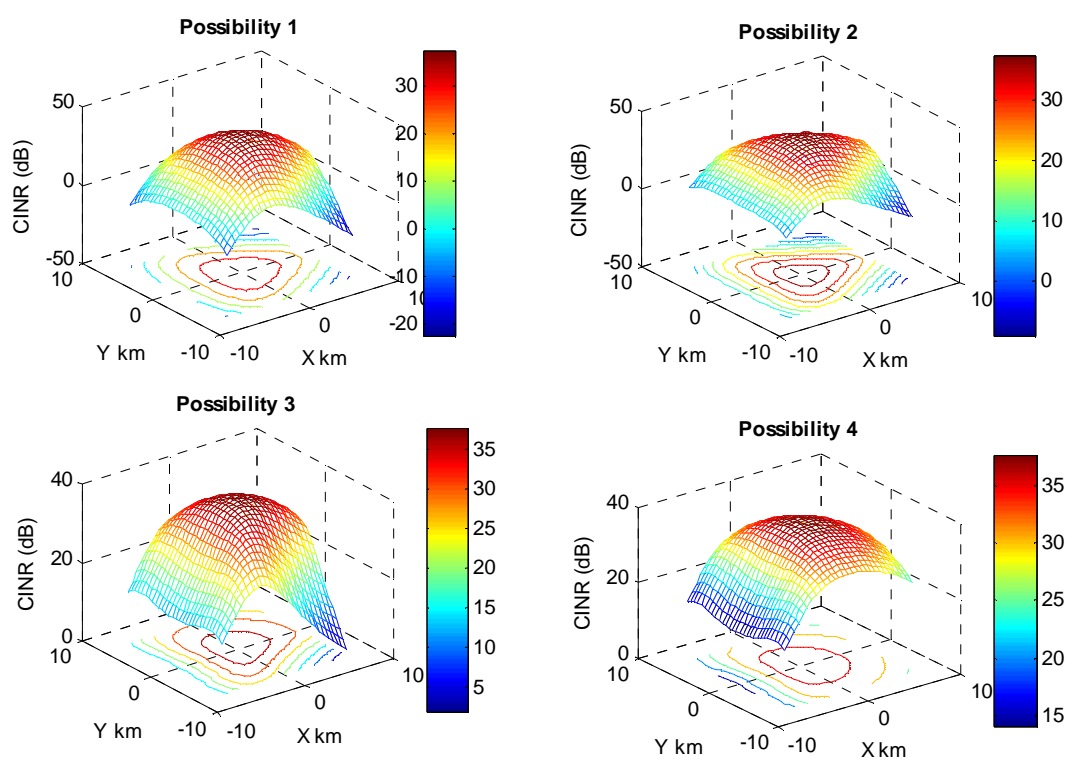

Figure 9 CINR user terrestrial in footprint exchange scenario using reuse factor $1 / 7$.
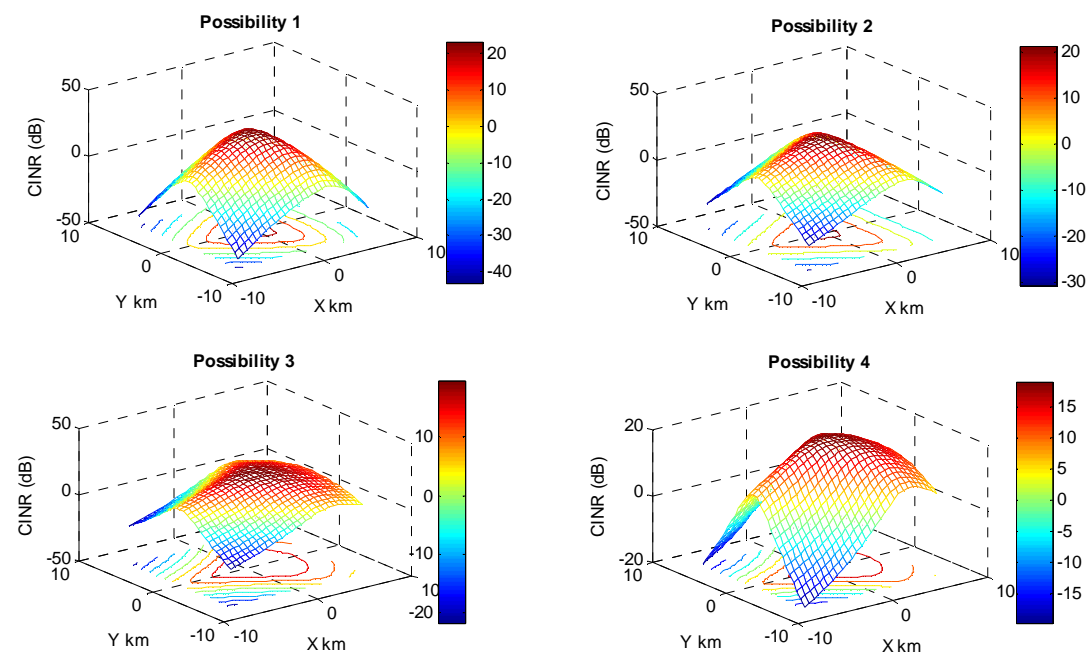

Figure 10 CINR HAPS user in footprint exchange scenario using reuse factor $1 / 7$. 

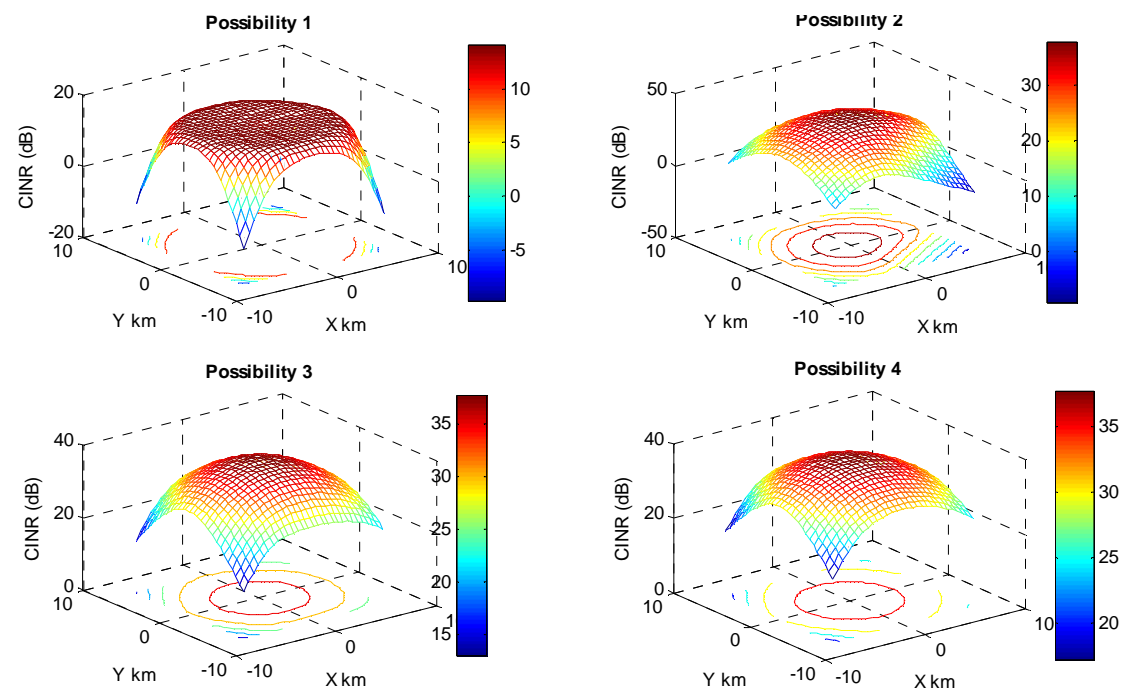

Figure 11 CINR perceived by a user HAPS in footprint exchange and cell HAPS enlargement scenario using reuse factor $1 / 7$.
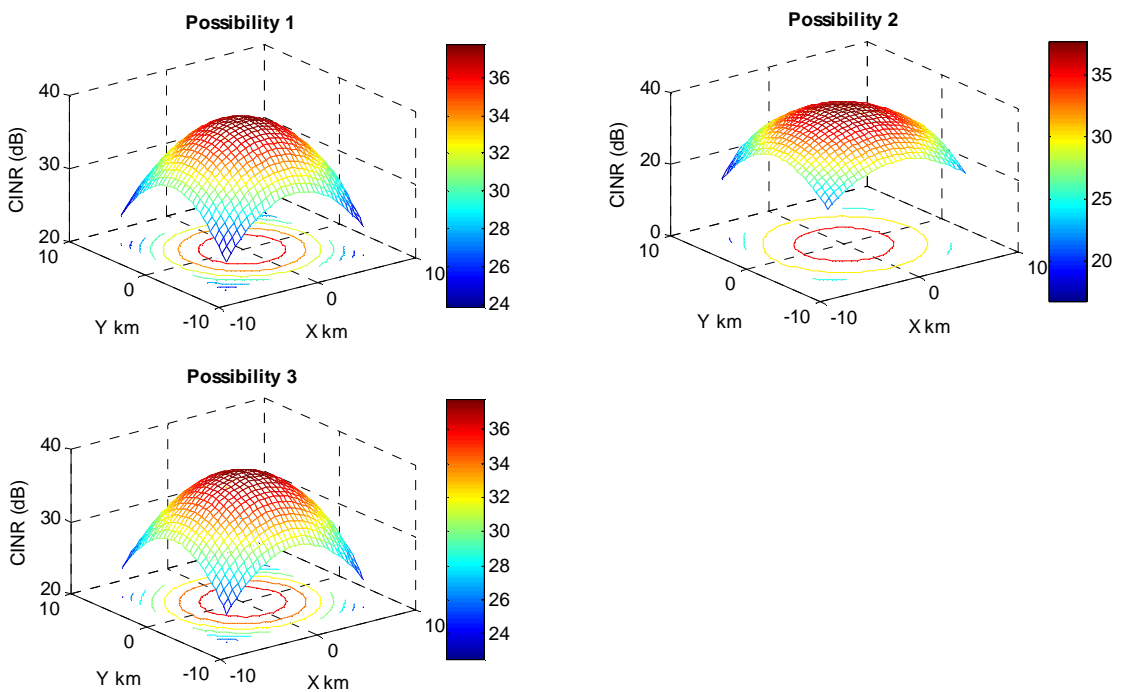

Figure 12 CINR perceived by a user terrestrial in footprint exchange and cell HAPS enlargement scenario using reuse factor $1 / 7$.

In the third scenario we combine between cell enlargement and footprint exchange method. This is done to improve CINR quality from the cell exchange 
method. Simulation results of the third method are described in Figure 11 for CINR perceived by user terrestrial and in Figure 12 for CINR perceived by user HAPS. Compared with both previous methods, this method has totally improved the CINR perceived by the user terrestrial and user HAPS because they are spreading out within the bigger cell area of HAPS coverage. To this result we have to deal with compromise between channel quality represented by high CINR value and reduction of the system capacity because of larger sell size. Of course it is not easy to be decided by operator since they are considering very good performance in a very high system capacity.

\section{Conclusion}

We have evaluated CINR performance of terrestrial users and also HAPS users for the application of WiMAX coexistence model between HAPS and terrestrial. It obvious that the method proposed in this paper has a significant effect on improvement the performance experienced by HAPS and terrestrial users compared to overlapping scenario. These proposed methods are provide an adequate quality of the channel to the coexistence system between Terrestrial and High Altitude Platform Station Mobile WiMAX. Based on the results of testing and analysis has been done in the previous section, it follows some of the following conclusions.

Both of the proposed methods provide improved performance experienced by users on both systems, terrestrial and HAPS. Cluster Size (N) a relatively greater interference would give smaller because the smaller Reuse Factor $(1 / \mathrm{N})$, the co-channel cells will be less and the distance of co-channel interference will be more distant. Magnification HAPS cells do not significantly affect the increase terrestrial CINR experienced user, but the effect on the area of performance. This is because the isolation of the propagation of the co-channel interference is quite good on the existing cellular system. Both of the proposed methods provide adequate channel quality for a system of coexistence between Terrestrial Mobile WiMAX and High Altitude Platform Station Mobile WiMAX.

\section{References}

[1] Yang, Z. \& Mohammed, A., Deployment and Capacity of Mobile WiMAX from High Altitude Platform, Vehicular Technology Conference (VTC Fall 2011), pp. 1-5, San Francisco, Sept. 2011.

[2] Imran, A. \& Tafazolli, R., Performance \& Capacity of Mobile Broadband WiMAX (802.16e) Deployed via High Altitude Platform, Wireless Conference, European, pp. 319-323, Denmark, May 2009. 
[3] Iskandar \& Putro, D.R., Performance Evaluation of Broadband WiMAX Services over High Altitude Platforms (HAPs) Communication Channel, The Fourth International Conference on Wireless and Mobile Communications (ICWMC '08), pp. 55-59, Athens, August 2008.

[4] Likitthanasate, P., Grace, D., \& Mitchell, P.D., Coexistence Performance of a High Altitude Platform and Terrestrial Systems Sharing a Common Downlink WiMAX Frequency Band, IET Journals \& Magazines, 41(15), pp. 858-860, 2005.

[5] Minimum Performance Characteristics And Operational Conditions For High Altitude Platform Stations Providing IMT-2000 in the Bands 1885$1980 \mathrm{MHz}, 2010-2025 \mathrm{MHz}$, and 2110-2170 MHz in the Regs. 1 \& 3 and 1885-1980 MHz and 2110-2160 MHz in Reg. 2, ITU-R M. 1456, 2000.

[6] Preferred Characteristics of Systems in the Fixed Service Using High Altitude Platform Stations Operating in the Bands 47.2-47.5 GHz and 47.9-48.2 GHz, Recommendation ITU-R F.1500, 2000.

[7] Oodo, M., Miura, R., Hori, T., Morisaki, T., Kashiki, K. \& Suzuki, M., Sharing and Compatibility Study between Fixed Service Using High Altitude Platform Stations (HAPS) and Other Services in the 31/28 GHz Bands, Wireless Personal Commun., 23, pp. 3-14, 2002.

[8] Iskandar \& Shimamoto, S., Channel Characterization and Performance Evaluation of Mobile Communication Employing Stratospheric Platforms, IEICE Trans. Commun., E89-B(3), pp. 937-944, March 2006.

[9] Djuknic, G.M., Freidenfelds, J. \& Okunev, Y., Establishing Wireless Communications Services via High Altitude Aeronautical Platforms: A Concept Whose Time Has Come?, IEEE Commun. Mag., 35(9), pp. 128135, 1997.

[10] Hase, Y., Miura, R. \& Ohmori, S., A Novel Broadband All-Wireless Access Network Using Stratospheric Platforms, Proc. $48^{\text {th }}$ IEEE VTC Spring, 2, pp. 1191-1194, 1998.

[11] Tozer, T.C. \& Grace, D., High-altitude Platforms for Wireless Communications, IEE Elec. and Commun. Eng. J., 13(3), pp. 127-137, 2001.

[12] Miura, R. \& Oodo, M., Wireless Communications System Using Stratospheric Platforms, J. Commun. Research Lab., 48(4), pp. 33-48, 2001.

[13] Grace, D., Thornton, J., Chen, G., White, G.P. \& Tozer, T.C., Improving the System Capacity of Broadband Services Using Multiple High-Altitude Platforms, IEEE Trans. on Wireless Commun., 4(2), pp. 700-709, 2005.

[14] Prasad, R. \& Velez, F. J., WiMAX Networks Techno-Economic Vision and Challenges, Springer, London, 2010.

[15] Ahason, S. \& Ilyas, M., WiMAX Technologies, Performance Analysis, and QoS, CRC Pres, Taylor \& Francis Group, Boca Raton, 2008. 
[16] Peng, Z. \& Grace, D., Coexistence Performance of High-Altitude Platform and Terrestrial Systems Using Gigabit Communication Links to Serve Specialist Users, EURASIP Journal on Wireless Communications and Networking- Special Issue: Advanced Communication Techniques and Applications for High Altitude Platforms, 2008, Article ID 892512, 11 pages, 2008.

[17] Rappaport, T.S., Wireless Communications: Principles and Practice (2nd Edition), Prentice Hall Communications and Emerging Technologies Series, 2002.

[18] Yang, Z., Mohammed, A. \& Hult, T., Performance Evaluation of WiMAX Broadband from High Altitude Platform Cellular System and Terrestrial Coexistence Capability, EURASIP Journal on Wireless Communications and Networking, 2008, Article no. 4, 7 pages, Sept. 2008.

[19] Sultan, J., Ismail, M., Misran, N. \& Jumari, K., Spectral Efficiency Evaluation of Downlink Mobile Multi-hop Relay Systems Employing Macro Diversity Handover Technique, IJCSNS International Journal of Computer Science and Network Security, 8(5), 2008.

[20] Yang, Z., Mohammed, A., Hult, T. \& Grace, D., Downlink Coexistence Performance Assessment and Techniques for WiMAX Services from High Altitude Platform and Terrestrial Deployments, EURASIP Journal on Wireless Communications and Networking, 2008, Article no. 3, Article ID 291450, 7 pages, 2008.

[21] Yang, Z., Grace, D. \& Mitchell, P.D., Downlink Performance of WiMAX Broadband from High Altitude Platform and Terrestrial Deployments Sharing a Common $3.5 \mathrm{GHz}$ Band, IST Mobile and Wireless Communications Summit, Dresden, June 2005.

[22] Yang, Z., Grace, D. \& Mitchell, P.D., Coexistence Performance of WiMAX in HAP and Multiple-Operator Terrestrial Deployments in Shared Frequency Bands, Communications Research Group, Department of Electronics University of York, York Yo10 5DD, United Kingdom, 2005.

[23] Thornton, J., White, A.D. \& Tozer, T.C., A WiMAX Payload for High Altitude Platform Experimental Trials, Communications Research Group, Department of Electronics University of York, York Yo10 5DD, United Kingdom, 2008.

[24] Thornton, J., Grace, D., Capstick, M.H. \& Tozer, T.C., Optimizing an Array of Antennas for Cellular Coverage from a High Altitude Platform, IEEE Transactions on Wireless Communications, 2(33), pp. 484-492, 2003.

[25] Dessouky, M., Nofal, M, Sharshar, H. \& Albagory, Y., Optimization of Beams Directions for High Altitude Platforms Cellular Communications Design, Proceedings of the Twenty Third National Radio Science Conference (NRSC 2006), pp. 1-8, Egypt, March 2006. 
CINR Performance of Downlink Mobile WiMAX IEEE 802.16e 83

[26] Gunasekaran, T., Veluthambi, N., Ganeshkumar, P., \& Kumar, K.R.S., Design of Edge Fed Microstrip Patch Array Antenna Configurations for WiMAX , IEEE International Conference on Computational Intelligence and Computing Research (ICCIC 2013), pp. 1-4, Enathi, Dec. 2013. 